\title{
Reviewers Never Change Their Spots - Or Do They?
}

Sindhu Menon

\begin{abstract}
The problems that the translators of books from English to other Indian languages face, including being almost ignored totally by reviewers, however irritating, is not a new phenomenon. This paper intends to demonstrate this by going to the archives and showing how the reviewers of the earliest review journals in England acted towards translations and translators from Greek, Latin and on very few occasions from other European languages. Even the mighty were not spared. So, nothing has really changed about the reviewers, they condescend to refer to the translator only when they want to comment on the deplorable work done, otherwise what one gets is a brief, laudatory essay on the original, complete with footnotes! It is as if the intermediary, the translator, does not exist, he is an absent presence. Yes, reviewers have never changed, at least until now, but the healthy trend is that the translators and the reading public have started to exchange opinions directly, leaving the now outsiders, the reviewers, out of the picture in several cases.
\end{abstract}

"The original is Unfaithful to the translation"

(Borges)

Combining my Anglophilia and my interest in antiquity, I decided to take for my primary texts in this paper, not contemporary translations, say from modern Indian languages into English and vice versa, but Translation from Greek and Latin and later from other European languages mainly into English and the reviews of those translations. Since many of those texts, critical as well as 'literary'

Translation Today Vol. 5 No. 1 \& 22008 C CIIL 2008 
have become part and parcel of the ENG LIT (English Literary) canon anywhere, including India, I felt that this was the apposite time to remind ourselves that we were conveniently forgetting the fact that Aristotle and Plato, who inevitably figure at the top of any critical course outline, actually wrote in Greek and that Homer, whose epics are welcomed with red carpets edged with purple into almost every English classroom did not even write, but recited in Greek. Horace and Virgil are also quite welcome and the fact that they were translated from Latin is conveniently forgotten. This applies to religious studies also; when we regularly debate in English classes if The Book of job is 'Literature,' we generally participate willingly in a mass agreement not to dwell on the fact that the original Bible was written in Hebrew, then underwent a stint in Latin and only after that was translated into English and even later, in the wake of the missionaries who followed the postcolonial trail, into the indigenous languages of some of the erstwhile colonies.

This train of thought led me to recognize that we also had no problem apparently with the contemporary texts in Literary Theory, most of which are translations from French, German or Russian. And this was not a matter for theory alone; Brecht and Ibsen as well as Racine or Voltaire was welcome, but a hard battle would have to be fought to include a translation of Ngugi's current writings.

This was an extremely ironic situation indeed where the entry of a text in any African language or in Malayalam or Hindi translated into English, for example, would be challenged at the gateposts, while the earlier translations from classical languages were not even regarded as translations any more and the contemporary translations from other European languages were admitted without any queries regarding their status. Indeed, one has to pause and wonder that while Chaucer could just about be managed with a good glossary, who but specialists in Old English could now cope with Beowulf without a 'translation'?

I wondered at this point if this had been always so, and if the reviewers of these early translators were all praise for their efforts. 
Current reviews of translated texts are largely summaries of the originals, and in several cases if the translator gets mentioned at all it is to face a series of accusations regarding her lack of fidelity to the source text. Today's reviewers of translated texts seem to be having their cake and eating it too with remarkable ease. On the one hand, the forcefulness with which they point out the translators' 'mistakes' and 'inaccuracies' is tantamount to a volatile re-accusation of the Italian adage 'traduttore, traditore' meaning 'translator, traitor,' while on the other hand they parade their expertise in both the source and target languages and suggesting oh-ever-so-innocently that they could have done the job much better.

Review Journals had of course flourished in English from a very early period, and I must admit that I started my research with the idea, or perhaps with the hope that things were better in those good old days. I am now in a position to affirm that that was not the case. As my title says, reviewers have not suddenly changed their spots, though today they lack the cut and thrust ability of riposte which had at least made the early reviews readable and are therefore easily caught out or spotted in their posturings. The one good aspect, in my opinion, about this initial stage in the translator vs. reviewer battle was that the early translators gave as good as they got, with both translator and reviewer indulging in extremely interesting if extremely unparliamentary language.

Today, a large group at least, among the translators seem to have either resigned themselves to the reviewers' criticisms or put on a mask of dignity which prevents them from retorting in the same manner. However, this is rarely perceived as dignity by the general reading public, who take the mass media reviewer as their mediator and guide and if her statements go unchallenged, then that is regarded as the ultimate proof of their veracity. Under the circumstances, it is definitely a worthwhile task to consider and discuss how or how not to review a translated text as it at least gives a reasonably clear indication of the fact that the translators are at last attempting to break their supposedly dignified silence and fight back. 
Reviewing has now become an almost mechanical activity, with the progressive steps to be followed set out with mathematical precision in books that can be called nothing other than set text books, and once these steps are internalized, it does not seem to make much difference whether the work under review is a translation or not. To give just one example, I will reproduce here the orderly, numbered steps arranged for the reviewer in Reviewing for the Mass Media (Hunt 3-8). There are eight specific points with elaborations of which I will only present the headings or rather dictates.

1. Above all, the reviewer informs his readers.

2. He raises the cultural level of the community.

3. He imparts personality to the community.

4. He advises readers how best to use their resources.

5. He helps artists and performers. (We are not talking about just book reviews here, but reviews of all forms of mass media).

6. He defines the new.

7. He records an important segment of history.

8. Not least of all, he entertains.

The last aspect at least cannot be denied its veracity in the initial stages of reviewing. As I mentioned earlier, the major bearable/ readable part of the early reviews, whether of translated texts or not, was their entertainment value. Who could not help being amused by Dorothy Parker's comment in her 'Constant Reader' column of The New Yorker of October 20, 1928, while reviewing Milne's House at Pooh Corner (1928) that when Pooh, in what she calls 'cadenced Whimsy', tells Piglet that 'I put that in to make it more hummy' (Rees 2003: 623) that 'And it is that word 'hummy,' my darlings, that marks the first place in The House at Pooh Corner at which Tonstant Weader fwowed up?" And can anyone manage to keep a straight face when Ms. Parker remarks in an as yet unidentified novel: 'This is not a novel to be tossed aside lightly. It should be thrown with great force?' And who would not laugh at Eugene Fields' comment on a performance of King Lear? ${ }^{1}$ : 'Mr. Clarke played the King all evening as though 
under constant fear that someone else was about to play the Ace?' (Rees 2003: 339).

One has to remember, however, that entertainment is but one and that too the last one in our list of "certain - success guaranteed - in - eight - steps' reviews manual. (And in all honesty, let us also admit that the entertainment value of most contemporary mainstream reviews has fallen far below the standards set by Dorothy Parker \& Co.) Still, after reading this manual of sure fire reviewing, one starts to feel really sorry for the writers and the translators. When mediating, defining, selecting, guiding and finally entertaining too are supposedly included in the reviewers' province, what exactly is left for an author to do, and from those scraps, what falls to the part of a translator?

It is indeed a relief to go somewhat further back from the witty repartee of the Algonquin Table and see that during the early stages of translation into English, the translators were quite capable of holding their own against any reviewer-and that was extremely necessary-considering the vituperative rather than witty nature of the expressions adopted by most reviewers.

Almost any student of English literature asked to name a good translator of Homer into English today, is sure to blurt out the name of George Chapman, whether they have read a work of his translation or not; as Keats' laudatory and memorable 'On Reading Chapman's Homer' (1884) is a must-read on most graduate English syllabuses. Unfortunately this tribute and its after effects came far too late as Chapman had finished his literary labours and passed away in 1614.

The reviewers of his time found fault with his translations, but he had little fear of them and his language was as vituperative as theirs, one of the milder terms he applied to his critics being 'envious windfuckers'! (Logue 2001: vii).

Ironically, the charges brought by reviewers and critics against those who dare to translate have remained unchanged in several 
respects from the Elizabethan era to the present century. The primary accusation is that of lack of fidelity to the original, of taking unwarranted liberties with the source text which ought to be regarded as sacrosanct. We see this charge in the review pages of contemporary newspapers and also as far back as the comments made by Chapman's detractors. Chapman's robust and confident stand, defending the liberties of the translator can be taken as a model reply to several carping reviews of even today. In his 'Preface to the Reader', published along with his translation of the Iliad, Chapman remarks:

How pedanticall and absurd an affectation it is, in the interpretation of

Any Author .... to turn him word for word, when (according

to Horace and

Other best lawgivers to translators) it is the part of every

knowing and

judiciall interpreter, not to follow the number and order of

words, but the

materiall things themselves. (Logue 2001: vii)

There were, of course, other translations of Homer, in both verse and prose, but before I approach the next most significant name in the area, that of Alexander Pope, I think a brief digression into John Dryden's opinions on the act of translation itself is justified. While conceding that his translation of the History of the League (1683) from French was undertaken by royal command and no real internal compulsion, his terminology in describing the process is still significant. While in the actual preface to the finished work, Dryden is extremely careful to make the work sound like a labour of love and also extremely urgent, his casual comments in the preface to a later verse collection is far more honest and revealing. In the preface to his Sylvae, Dryden tells us:

For the last six months I have been troubled with the disease of translation, the cold prose fits of it, were spent on the History of the League, the hot, on this volume of verse miscellanies. (Winn 1987: 395) 
'The disease of translation' - an incredibly relevant description indeed, from a sustained analysis of which one could probably garner the basic assumptions of the various attitudes of various times which have consistently implied and stated that translation is at best a secondary activity, never one which can measure up to the act of original composition irrespective of quality and is at best a utilitarian and profit oriented task unworthy of the true creative muse. From here, the move to Pope's comments in his 'Preface' to his translation of the Iliad are while chronologically close, quite a distance ahead in tone. Certainly, compared to Chapman's aggressive assertion and Pope's own well known talent for invective, the comments in the 'Preface' seem incredibly tame and compromising, but at least they place the activity of translation in a higher position than Dryden accords to it. Pope comments:

It should then be considered what methods may afford some equivalent in our language for the graces of these in the Greek. It is certain no literal translation can be just to an excellent original in a superior language, but it is a great mistake to imagine (as many have done) that a rash paraphrase can make amends for this general defect, which is no less in danger to lose the spirit of an ancient, by deviating into the modern manners of expression. If there be sometimes a darkness, there is often a light in antiquity, which nothing better preserves than a version almost literal. I know no liberties one ought to take, but those which are necessary to transfusing the spirit of the original, and supporting the poetical style of the translation; and I will venture to say, there have not been more men misled in former times by a servile, dull adherence to the letter, than have been deluded in ours by a chimerical, insolent hope of raising and improving their author. It is not to be doubted, that the fire of the poem is what a translator should principally regard, as it is most likely to expire in his managing; however, it is his safest way to be content with preserving this to his utmost in the whole, without endeavouring to be more than he finds his author is, in any particular place. It is a great secret in writing, to know when 
to be plain, and when, poetical and figurative, and it is what Homer will teach us, if we will but follow modestly in his footsteps. Where his diction is bold and lofty, let us raise ours as high as we can, but where his is plain and humble, we ought not to be deterred from imitating him by the fear of incurring the censure of a mere English critic. Nothing that belongs to Homer seems to have been more commonly mistaken than the just pitch of his style, some of his translators having swelled into fustian in a proud confidence of the sublime, others sunk into flatness, in a cold and timorous notion of simplicity. Methinks I see these different followers of Homer, some sweating and straining after him by violent leaps and bounds (the certain signs of false mettle), others slowly and servilely creeping in his train, while the poet himself is all the time proceeding with an unaffected and equal majesty before them. However, of the two extremes one could sooner pardon frenzy than frigidity, no author is to be envied for such commendations, as he may gain by that character of style, which his friends must agree together to call simplicity, and the rest of the world will call dullness. There is a graceful and dignified simplicity, as well as a bold and sordid one, which differ as much from each other as the air of a plain man from that of a sloven: it is one thing to be tricked up, and another not to be dressed at all. Simplicity is the mean between ostentation and rusticity.

(Barnard 1973: 67)

The dispute regarding the proper function of translation, as to whether it is to provide a mimetic duplicate or to convey a sense of the potential of the original to the reader by deliberately creative and original methods, seems to have confounded even Pope to the extent of making him provide statements in his 'Preface' which really subscribe completely to one viewpoint or the other. But indeed, when, instead of using the hammer blows which Pope could counter easily through inclusion in his Dunciad, his critics went in for swift thrusts like this by Richard Bentley. 'It is a very pretty poem, Mr. Pope, but 
you must not call it Homer' (Johnson 1905: 54). It is small wonder that even Pope who excelled at invective should have his doubts about the position and ranking of the task he was undertaking.

Indeed, the constant dual accusations levelled against translators, one best exemplified in Robert Frost's comment that 'Poetry is what gets lost in the translation' which charges the translator with 'losing the fire of the original' or the other which accuses her of not following the original slavishly and of daring to innovate with the source text which is to be regarded as sacrosanct are enough to confuse the most confident translator. Indeed, the English terms of source text and target text fail to convey the imperativeness of the second attitude which is made extremely clearer in the Indian terms of 'Swami-Bhasha' (Master Text) and 'Dasya-Bhasha' (Servant text).

Even under these circumstances, one could rank Chapman and Pope among the more fortunate as they are at least remembered as translators. The fate of their contemporaries who must have laboured equally hard in the translations of prose texts like those of Aristotle or Plato is far worse-obscurity or complete invisibility. How many of us today, who teach or learn Aristotle, Plato, Horace or Longinus, to name the canonized few in English Literary Criticism classes, know or even care about the identity of the translator? And while deconstruction for instance, retains some of its novelty, Spivak may be fortunate enough to be remembered as the translator of Derrida, but observing trends till now, her reputation, if it is to be sustained, must remain based on her 'original' writings; as translators of Foucault, Barthes and several others are relegated to mentions in a corner of the copyright page, Spivak's fame or rather notoriety is sustained far more by her 'Introduction' condemned by many as more incomprehensible than Derrida himself, and cannot be expected to prop the work up forever.

While there are new names being coined now, from transcreation to rewriting, the fact remains that translators get very few of the bouquets and far more than their share, of the brickbats. 
The situation in India is extremely peculiar and perhaps unique, while we accept translations from both the ancient European languages such as Greek or Latin, or from contemporary works of theory or fiction from French, German, Mexican or Russian without the slightest qualm as 'English' into our classrooms and canons, all hell breaks loose when a similar translation from any of our own 'regional languages' are attempted to be included in the syllabus.

The reaction, especially visible in the review columns where the reviewer insists on the worthlessness of the translation, principally as it amounts, irrespective of quality, to a degradation of the original Indian language, would be incomprehensible if we did not have what I would call two opposing colonial models already in front of us. These two methods, which were applied to the translations from Indian languages produced by the orientalists could be called the 'Macauleyan' and the 'Millean' respectively - the first embodied perfectly in Macaulay's Minute and consists of brushing aside the very existence of such translations as irrelevant, and the second exemplified by James Mill's technique of using the translations of fictional and legendary texts for precisely the one purpose they were most unsuited for-that garnering so-called historical (and mainly condemnatory) 'facts.'

The prejudice that reviewers and critics of the colonial and initial post-colonial period applied to translations considering these degrading uses they were put to, is understandable. But surely, the time for a change of attitude has come, when we are technically at least more than a good century away from the colonial period and the translators are no longer Coloniser-orientalists with suspect motives, but Indians with a sincere desire to make texts in one 'regional language' accessible to those who are ignorant of it. It would indeed be a utopia if all translations among Indian texts could be from one 'Indian' language into another, but utopia is always by definition over the horizon, and even if we overlook the sheer numerical contrast between the number of translations and those of shared reading communities such a project would involve, it is surely high time that we acknowledged that as aunty-tongue or mother-in-law tongue, 
English is now as much of an Indian language as any other, and therefore one with which we can afford to take liberties? Such a recognition should ensure that the translators into English are not automatically regarded as betrayers or polluters of the original language.

The question of how to or how not to review translated texts, gains importance especially therefore in the Indian context, where the reviews can decide the acceptance or dismissal of a translation. There is indeed no doubt that readability still remains an important aspect of reviews, but this need not and indeed should not take the role of personal vindictiveness, which merely spurs further offensives and counter offensives in the midst of which the text sinks without a trace. Also, if there are 'faults' so to speak, it is certainly a part of the reviewers' task to point them out. This had to be done with a much belated awareness that reviews are not the places to parade one's own scholarship to the detriment of the work under consideration. And as far as translations into English are concerned, it would be well if the reviewers remembered that the issue at stake here is not merely one of whether the work shall sell or not and that there is an ongoing struggle in the academia, sadly problematical though absurd as it is, to convince syllabus makers that if Tolstoy and Plato, and Marquez and Borges are acceptable in English class rooms, there can be no reason why English translations from Malayalam or Telugu or Urdu or Hindi cannot be accorded at least the same status. Unfortunately we can still see the attitude; adopted perhaps because of an overzealous patriotism, of continuing to regard English as the enemy. This, often in conjunction with a mean spirited desire to parade the reviewers' own multilingual skills as far better than the translator's could delay the acceptance of texts translated from Indian languages. To those reviewers of the first persuasion one can but strive to point out that time has not stood still, while those who adopt the second attitude need to be firmly informed that half a page review columns are not meant for such parading of virtuosity and any such desire would be better represented if they too were to go and engage themselves in the actual act of translation. 
Note

1. Field was referring to Creston Clarke's performance of King Lear in Denver in 1880 .

\section{References}

Barnard, John (1973) Pope: The Critical Heritage, London: Routledge.

Chapman, George (1998) in Allardyce Nicoll (ed.) Chapman's Homer: the Iliad, Princeton: California University Press.

Hunt, Todd (1972) Reviewing for the Mass Media, Philadelphia: Chilton.

Johnson, Samuel (1905) "Life of Pope" in G.B. Hill (ed.) Lives of the English Poets 3 vols. Oxford: Clarendon.

Logue, Christopher (2001) War-Music, London: Faber and Faber.

Rees, Nigel (2003) Cassel's Humorous Quotations, London: Cassell.

Winn, James Anderson (1987) John Dryden and His World, New Haven: Yale University Press. 